To be published in: Sabine Maasen, Mario Kaiser, Monika Kurath \& Christoph Rehmann-Sutter (eds.): Deliberating Future Technologies: Identity, Ethics, and Governance of Nanotechnology, Heidelberg et al.: Springer, 2008.

\title{
From Nano-Convergence to NBIC-Convergence: "The best way to predict the future is to create it"
}

\author{
JOACHIM SCHUMMER \\ Department of Philosophy, University of Darmstadt, Germany \\ js@hyle.org
}

\begin{abstract}
:
This chapter combines rhetorical with conceptual analysis to argue that the concept of convergence of technologies is a teleological concept that does not describe or predict any recent past, present, or future development. Instead it always expresses or attributes political goals of how future technology should be developed. The concept was already fully developed as a flexible rhetorical tool by US science administrators to create nanotechnology (as nano-convergence), before it was broadened to invent the convergence of nano-, bio-, info-, and cogno-research (NBIC-convergence). Analyzing the use of "convergence" in various US reports, such as in convergence did, does, can, will likely, will necessarily, should, and ought to happen, sheds new light on how science policy avoids public debates about goals and values in deliberating the future, which poses new challenges to STS.
\end{abstract}

\section{Introduction}

Since nanotechnology has been touted to bring about the next industrial revolution, ${ }^{1}$ the talk about nanotechnology has considerably shifted towards the future. Given the notorious fuzziness of the concept of nanotechnology, various actors have employed the future to define the field by reference to its future "societal and ethical implications" (Schummer 2004c). Sometimes the futuristic ideas of nanotechnology become so removed from the present research which scientists call nanotechnology that it is difficult to see any connection. In order to bridge the gap between the present and the future, various tools have been developed, including prognostic tools of technology foresight and assessment as well as conceptual tools that conceive of technology as process rather than as products or states. In this paper I analyze another powerful conceptual tool for connecting the presence to future: the concept of convergence and its use in US reports on nanotechnology.

It would seem that the concept of convergence was first employed in the so-called NBIC report, which suggested the convergence of nanotechnology, biotechnology, information technology, and the cognitive science for improving human performance (Roco and Bainbridge 2002). However, as I argue in Section 2, the concept and its various rhetorical uses to connect the present to the future were already fully developed in the early science policy idea of nanotechnology as nano-convergence. Section 3 examines how the tool was transferred to the idea of NBIC-convergence by widening the scope of technologies and by stating the explicit goals of human enhancement. My procedure simply consists in analyzing the meaning of various sentences, such as convergence did, does, can, will likely, will necessarily, should, and ought to happen, which all appear in the reports. I argue that in all these modes the talk of convergence is a more or less encrypted form of stating and attributing

\footnotetext{
$1 \quad$ "Supporting the Next Industrial Revolution" has been the motto of the US National Nanotechnology Initiative since its launch in January 2000. The term "nanotechnology revolution" goes back to a book coauthored by Eric Drexler (Drexler, Peterson, and Pergamit 1991) which further developed his specific vision of molecular nanotechnology.
} 
goals. Section 4 examines more systematically why the concept of convergence is such a flexible rhetorical tool by analyzing the teleological nature of the concept. In conclusion I argue that the science policy induced shift towards deliberating the future poses various new challenges to STS, of which analyzing the talk of convergence is but one example.

\section{The Rhetoric of Nano-Convergence}

\subsection{Convergence-as-fact}

In early 2000, the National Science and Technology Council, Subcommittee on Nanoscale Science, Engineering, and Technology (NSTC/NSET) asked the National Science Foundation (NSF) to organize a workshop from which a report should be produced on the Societal implications of nanoscience and nanotechnology (Roco and Bainbridge 2001). Mihail C. Roco, Director of the then freshly established National Nanotechnology Initiative (NNI), and William S. Bainbridge, then Director of NSF's division for social and behavioral sciences, became in charge of the project. They promptly organized a workshop in September 2000 and published the report in March 2001. Their Executive Summary starts with the remarkable claim:

"A revolution is occurring in science and technology, based on the recently developed ability to measure, manipulate and organize matter on the nanoscale -1 to 100 billionths of a meter. At the nanoscale, physics, chemistry, biology, materials science, and engineering converge toward the same principles and tools. As a result, progress in nanoscience will have very far-reaching impact." (Ibid., 1)

Roco and Bainbridge suggested here that, because of some unspecified recent scientific achievements, almost all the science and engineering disciplines were converging toward the same principles and tools. They argued that this convergence itself was a true revolution, which, in case of further progress, would also lead to far-reaching societal impacts. However, the two components of their revolution claim, the convergence of disciplines and the recent scientific developments that would have induced the convergence, remain questionable. In lack of further specification, we may only speculate what they had in mind.

The "recently developed ability to measure, manipulate and organize matter on the nanoscale" (ibid.) could mean many abilities or only one. To be sure many of the mentioned disciplines have in the past decades further developed their synthetic capacities in the nanoscale, including combinatorial chemistry, stereoselective synthesis, chemical vapor deposition, recombinant DNA technology, lithography, and so on. However, they have done that permanently during the 20th century, and it is questionable how such diverse developments should suddenly bring about the convergence of the disciplines. It is more likely that Roco and Bainbridge referred to scanning probe microscopy (SPM), which had been developed since around 1980 and indeed had very soon been widely adopted by many science and engineering disciplines. However, that technique has been widely used only as an analytical tool to analyze surfaces, rather than to "manipulate and organize matter on the nanoscale" (ibid.). Other analytical tools developed since the first half of the 20th century, like x-ray diffraction, nuclear magnetic resonance, and various spectroscopies, were equally adopted by many disciplines, which in the same period enjoyed further disciplinary divergence rather than convergence. It seems therefore that Roco and Bainbridge referred to the discovery of the late 1980s that one can also scratch on crystal surfaces with the tip of an SPM and that under extreme conditions one can move with the tip single surface atoms. While electrical engineers still explore that approach as an alternative to IC lithography, it has never yielded the slightest promising results as an effective engineering approach to "manipulate and organize matter" in any other discipline up to today. Thus it is more likely 
that Roco and Bainbridge referred to some envisioned future science rather than to the actual science and technology practice as they pretended to do.

Similar to the obscure tool, it remains unclear what they meant by convergence of the science and engineering disciplines toward the same principles. Obviously they were not willing to repeat the standard physicalist reductionism story and thus did not refer to the axioms of quantum electrodynamics or the particles of particle physics. Instead, as their Introduction to the Report makes clear, they were referring to the "basic building blocks" of the world by which they meant "atoms and molecules". However, our present concepts of atoms and molecules originate from early 19th-century chemistry. While these concepts indeed enjoyed extraordinary success during the entire 20th-century and became used in any natural science and engineering discipline other than software engineering, there is no evidence of any recent disciplinary convergence in that regard. For instance, physics owes much of its modern identity to its quest for the "basic building blocks" in sub-atomic particles, from baryons and hadrons (e.g. electrons and neutrons) to quarks and strings, and there is not the slightest evidence that physicists are suddenly giving up that idea. In biology, dropping the simplistic idea of molecular building blocks in favor of systemic and informational approaches led to the split of molecular biology from biochemistry in the mid20th century, again with no indications of a recent return. Materials science established itself as an independent discipline since the 1970s by carving out research fields from chemistry and physics, and they show no inclination to reverse the history. While all the disciplines still use terms such as "molecule", the meaning of these terms have diverged rather than converged, because they developed their own models and theories that provided new disciplinary meanings to the terms (Schummer 2004b). The increasing lack of common principles might be regrettable, if one prefers stronger interdisciplinary research collaboration, but it nonetheless remains a history of science fact. ${ }^{2}$

I conclude therefore that Roco and Bainbridge had little to no evidence for claiming a sudden revolution in the recent scientific development based on the convergence of the disciplines because of some new synthetic tools or common principles. Their claim is an incidence of describing the desired future convergence as if it were a fact of the presence or recent past. The rhetorical topos is well known. They suggested that there was no need to question the goal of convergence because it had already happened.

\subsection{Convergence-by-higher-necessity}

Shortly after the NNI was established, the National Research Council (NRC), an agency of the private National Academy of Sciences, was commissioned to review the efforts of the NNI up to then. To that end the NRC established a committee consisting of representatives from academia and private business. In their report of 2002, they made another remarkable claim about the convergence of disciplines:

"Nanoscale science and technology are leading researchers along pathways formed by the convergence of many different disciplines, such as biology, physics, chemistry,

\footnotetext{
2 As a funding agency the NSF itself represents this paradox: On the one hand, its organization is divided into disciplinary directorates that distribute money to the corresponding classical disciplines (except for the biomedical science for which the NSF is not responsible!), and the bigger the organization grows, the more disciplinary subdivisions emerge. On the other, there are increasing efforts to support interdisciplinary research, including special programs for "cross-cutting research", an "Office of Multidisciplinary Research", the recent inclusion of the "transformative research" criterion in proposal evaluations, and, last but not least, the share of the NNI budget administered by the NSF (see www.nsf.gov). Indeed, the whole nanotechnology movement epitomizes the science policy intention to break up the disciplinary funding structure against the long-term historical trend, such that the talk of convergence is only the latest rhetorical step in that direction; see also note 3.
} 
materials science, mechanical engineering, and electrical engineering." (National Research Council 2002, 2, similar on pp. 16, 47)

At first glance, the claim appears similar, if not identical, to the claim made by Roco and Bainbridge a year before. However, the context in which that claim appears makes unmistakably clear that the NRC committee assumed just the opposite. Indeed, they argued at length that there was insufficient interdisciplinary collaboration between the disciplines, which meant that in the actual research practice there was anything else than convergence of the disciplines. And so, as one of their ten main recommendations, the committee suggested as a remedy to "provide strong support for the development of an interdisciplinary culture for nanoscale science and technology" (ibid., 3). ${ }^{3}$ Indeed, a scientometric study of the crossdisciplinary research collaboration in all major nanotechnology journals makes clear that, while each of the classical disciplines has embraced the nano-label, they all do their own "nanotechnology" with no remarkable degree of interdisciplinarity (Schummer 2004a).

While Roco and Bainbridge, contrary to all evidence, talked of convergence as if it were a fact of the presence, the NRC committee employed a subtler rhetorical means, which is worth analyzing in more detail. The phrase "Nanoscale science and technology are leading researchers along pathways formed by the convergence of many different disciplines" (ibid., 2) suggests first that there are some mysterious agents at work that are leading researchers and which are called "nanoscale science and technology". It further suggests that there are predetermined pathways for each of the disciplines, and that the mysterious agents only help the disciplines find their proper way to their own predetermined destiny. And the common destiny of the disciplines is, of course, convergence. How can we make sense of such a mysterious story in an official report? I suggest that there are two intertwined readings.

On the one hand, the story expresses the metaphysical view of technological determinism. In this view, the development of science and technology follows a predetermined pathway towards the goal of disciplinary convergence. The mysterious agents called "nanoscale science and technology" are but ideas that capture the "proper" goal of the disciplines and thus help researchers find their predetermined pathway. As a metaphysical view, technological determinism is the most naive idea about science and technology development that disregards virtually anything we know about their social dynamics. As a rhetorical figure, however, which incidentally resonates with the Christian eschatology, it provides strong guidance to the extent that any alternative way appears unnatural, i.e. contrary to the predetermined natural course of events.

There is also a more mundane reading of the mysterious story. Given that the story appeared, and indeed frequently appears, in science policy contexts, the mysterious agents called "nanoscale science and technology" could be nothing else than governmental agencies - here, the National Nanotechnology Initiative, which actually represents all the federal research-funding agencies in the US. In this reading, the agencies are unhappy with the disciplinary structure of science and technology because disciplines tend to focus on idiosyncratic academic problems instead of dealing with problems of general societal concern. Thus, they might have decided that future funding must increasingly be channeled to research that disregards disciplinary boundaries. In this reading, the goal of convergence is equivalent to breaking up the disciplinary identities, and the NNI is but a helping meta-agency that leads researchers "along pathways formed by the convergence".

Both readings are intertwined in the sense that the metaphysical reading and its rhetorical effect help convince scientists of following the goals of the political agenda.

\footnotetext{
3 This recommendation has been translated into NSF's nanotechnology funding policy which mainly supports interdisciplinary research centers for a limited period. It is questionable however if that policy has any long-lasting effects, once the center funding stops (Schummer 2007a).
} 


\subsection{Convergence-as-opportunity}

Another popular way of framing the convergence of disciplines is by pointing out the extraordinary opportunities that the convergence will open up to society. Indeed, almost the entire report on Societal implications of nanoscience and nanotechnology (Roco and Bainbridge 2001) consists in praising nanotechnology because of the unprecedented health, wealth, security, and so on that it will bring to society. While pointing out opportunities has become standard language in science and technology reports, it is not very clear what it actually means and what its implicit message is. It is a specific way of talking about the future that is clearly distinguished from the previously discussed formulations of convergence-asfact and convergence-by-higher-necessity.

Opportunities are more than mere possibilities or feasibilities. Before pointing out the opportunity of something, the reports always assure us that this something is technologically feasible in principle. A recurrent phrase is, "It can be done. It is only a matter of time." As a rule, the only obstacles or "challenges" that are listed are social rather than scientific obstacles, e.g. insufficient funding, unfocused research efforts, lack of interdisciplinary collaboration, and so on. Thus, because opportunities presuppose technological feasibilities, they are possibilities whose realization depends only on social factors.

Moreover, opportunities are well-selected possibilities. No report provides a list of all technologically feasible possibilities, and hardly any report provides several possibilities as options to chose from. ${ }^{4}$ Instead, the reports usually list many opportunities that can altogether be seized by the same possible technology, once the social obstacles are overcome. The criteria for selecting possibilities as opportunities are exclusively social criteria. A possible technology is an opportunity only because it is said to meet the goals of society. And since the opportunities are not offered as options to chose from, depending on one's personal preference, the talk of opportunities expresses a very determined view of what the goals of society actually are, what society expects from scientists.

The talk of opportunities of a possible technology, or of the possible convergence of technologies, thus turns out to be rather about society than about technology. In a cryptic manner it criticizes society because of its irrationality: Because of social obstacles, society is unable to achieve what it actually desires. If addressed specifically to scientists and engineers who are unwilling to converge, the talk of the opportunities of convergence has a clear moral message: You are not doing your duty, what society expects you to do.

Like convergence-by-higher-necessity, convergence-as-opportunity is a cryptic form of talking about goals and norms, about what should or ought to be done rather than about what happens or what are possible options.

\section{NBIC-Convergence}

\subsection{From Nano-convergence to NBIC-convergence}

When Roco and Bainbridge published their 2002 report on Converging Technologies for Improving Human Performance: Nanotechnology, Biotechnology, Information Technology and the Cognitive Science (Roco and Bainbridge 2002, in the following also called NBIC report), they seemed to imply that nanotechnology already existed as a discipline that is ready to converge with other disciplines. The "revolution" of nano-convergence they had claimed only a year before, according to which "physics, chemistry, biology, materials science, and engineering converge toward the same principles and tools" (Roco and Bainbridge 2001, 1), appeared to be no longer a matter of the present or future, but a matter of the past. I assume,

$4 \quad$ A notable exception is the European response to the NBIC-report (Nordmann 2004). 
however, they had simply changed their mind about the scope and arrangement of the disciplines that should converge and about the goals of convergence. Indeed, the idea of nanotechnology in NBIC-convergence was no longer the original idea of nanotechnology in nano-convergence, because it was now deprived of its original biological and engineering components and became largely a proxy for materials science, chemistry, and physics. Thus, rather than letting one convergence follow after the other, they widened the scope, regrouped the disciplines that should converge, and formulated the specific goal of human enhancement. It should be noted that the idea of NBIC convergence was not new but already discussed by the Interagency Working Group on Nanoscience, Engineering and Technology (IWGN) when they prepared the launch of the NNI. For their 1999 report on Nanotechnology Research Directions (NSTC/IWGN 1999), the IWGN, which was chaired by Roco, hired as Public Affairs Consultant John Canton, who entertains a website called futureguru.com, to provide a visionary look into the future of nanotechnology. Indeed, Canton provided the template of what later would be called NBIC-convergence:

"The convergence of nanotechnology with the other three power tools of the twentyfirst century - computers, networks, and biotechnology - will provide powerful new choices never experienced in any society at any time in the history of humankind." (Canton 1999, 179)

I assume therefore that the political success of the NNI, i.e. that all disciplines were jumping on the bandwagon and attaching the nano-label to their mono-disciplinary research, encouraged Roco and others to consider nano-convergence only a test phase, a preliminary step towards the bigger project of NBIC-convergence.

\subsection{The Ideas and Articulations of NBIC-convergence}

Unlike the reports produced by the IWGN and NNI, the NBIC-report is not an official document commissioned by any governmental agency; instead, it is based on a workshop sponsored by the NSF and the Department of Commerce and conducted by Roco and Bainbridge. However, it is composed exactly like an official report, with contributors from government, academia, and the private sector; an executive summary with recommendations to governmental agencies; and, last but not least, it is co-edited by the director of the NNI.

The central idea of the report is to orientate the research of all the disciplines involved towards the goal of enhancing certain human capacities, including physical, intellectual, and social capacities. For instance, physical enhancement includes new sensory abilities through electronic sensor implants, exo-skeletons or bullet-proof armors that support physical strength, robotic war fighter systems, and measures to "control the genetics of humans" (Roco and Bainbridge 2002, 5), etc. Intellectual enhancement includes transportable supercomputers, brain-computer interfaces, and a "hierarchical intellectual paradigm" (ibid, 6) for understanding the world. Social enhancement includes brain-to-brain interfaces for better communication, new management principles based on an atomistic understanding of human culture, and a new unified educational paradigm.

Apart from nano-, bio-, and computer-technology, a field called "cogno science" should also be involved according to Roco and Bainbridge. That seems to include such diverse things as cognitive psychology, neurophysiology, software engineering, sociology, ethology, and so on, in so far as these disciplines are committed to a systems theory approach or to what Canton in 1999 called network thinking.

How was the NBIC-convergence idea articulated? If one ignores the numerous other authors, Roco and Bainbridge provided two different versions in the NBIC report. In their "Executive Summary" they chose the "convergence-as-opportunities" version. That is, they did not claim that NBIC-convergence was already happening, but pointed out that, because of some recent scientific achievement, now would be the best time to start with. They argued 
that, if the disciplines converge towards the enhancement goals, these goals could be achieved within 10-20 years. And, of course, as they did before in their Societal implications of nanoscience and nanotechnology report, they praised the goals as unique opportunities to society that ought not to be missed out because they would bring unprecedented health, wealth, power, security, and so on. In the manner of an official report, they concluded, on behalf of all workshop participants, with the recommendation of "a national R\&D priority area on converging technologies focused on enhancing human performance" (ibid, xii).

In his own workshop paper on "Coherence and Divergence of Megatrends in Science and Technology" (Roco 2002), Roco chose two different versions. At first, he employed the "convergence-by-higher-necessity" theme. He started with identifying six "megatrends", which not incidentally comprise the NBIC field, and which he called (1) Information and computing, (2) Nanoscale science and engineering, (3) Modern biology and bioenvironmental approaches, (4) Medical sciences and enhancement of the human body, (5) Cognitive sciences and enhancement of intellectual abilities, and (6) Collective behavior and systems approach. Then he claimed that the "megatrends" 1-4 were naturally converging: "The nano, bio, and information megatrends extend naturally to engineering and technology, have a strong synergism, and tend to gravitate towards one another." (Ibid., 82) In order to harvest the full synergy of this "natural" convergence focused on "human development", he argued, one needs to consider the full scope "from individual medical and intellectual development to collective cultures and globalization" (ibid., 83). From that he reasoned that the remaining two "megatrends" must be integrated as well. The teleological argument here seems to be that the "natural" goal of the deterministic convergence is better met by integrating the other two trends. Then, after a lengthy review of the NNI and his own role therein, Roco made a sharp turn and pointed out the need of strong political guidance: "Professors do not leave their students to do everything they like in academic research. On the contrary, if a research project goes well, more resources are guided in that direction. This idea should be held true at the national level, where there are additional advantages such as synergistic and strategic effects." (Ibid., 94)

It seems that in practice Roco has always, from nano-convergence to NBICconvergence, followed the idea of convergence-by-creation, according to his slogan "The best way to predict the future is to create it" (ibid., 94). Although the NBIC-report was no official report and although no official report has ever been commissioned by the NNI on the NBIC issues, it eventually found its way into the official science policy agenda of the US. In the Supplement to the President's FY 2007 Budget for the NNI, where all agencies have to explain their activities, the NSF states:

"Special emphasis will be placed on research in the following areas:

$[\ldots]$

- Merging science and engineering at the nanoscale: the convergence of nanotechnology with information technology, modern biology, and social sciences will stimulate discoveries and innovation in almost all areas of the economy." (NSTC/NSET 2006, 5)

\subsection{The Friends of NBIC-convergence}

The list of the human enhancement goals, to which most of our natural, engineering, and social sciences should be bound according to Roco and Bainbridge, expresses their particular normative idea of what the ideal human being is, what kind of human capacities should be valued and deserve enhancement. In this picture of the ideal human being there is an almost complete lack of emotional, moral, and political capacities, while social capacities are reduced to the exchange of information, obedience to a kind of totalitarian order, and the removal of disagreement by unified indoctrination. What is particularly valued instead are 
physical strength and invulnerability, extraordinary sensory abilities like infrared night sight, and the ability to process large amounts of information in short time.

It is no coincidence that this image of the ideal human being almost exactly matches the capacities expected from the perfect soldier in combat. Indeed, many of the enhancement examples are explicitly taken from the military area, like armors that support physical strength and robotic war fighter systems. Moreover, a whole section of the NBIC-report is devoted to "National Security", with representatives from all major military agencies. For instance, Michael Goldblatt from the Defense Advanced Research Projects Agency (DARPA) explained the military interest in human enhancement as follows:

"With the infusion of technology into the modern theater of war, the human has become the weakest link, both physiologically and cognitively. Recognizing this vulnerability, DARPA has recently begun to explore augmenting human performance to increase the lethality and effectiveness of the warfighter by providing for super physiological and cognitive capabilities." (Goldblatt 2002, 337)

The summary of the military workshop section explains why NBIC-convergence is particularly important to that end. For instance,

"Applications of brain-machine interface. The convergence of all four NBIC fields will give warfighters the ability to control complex entities by sending control actions prior to thoughts (cognition) being fully formed. The intent is to take brain signals (nanotechnology for augmented sensitivity and nonintrusive signal detection) and use them in a control strategy (information technology), and then impart back into the brain the sensation of feedback signals (biotechnology)." (Roco and Bainbridge 2002, 329)

Another example is genetic or biochemical engineering of the human body:

"Non-drug treatments for enhancement of human performance. Without the use of drugs, the union of nanotechnology and biotechnology may be able to modify human biochemistry to compensate for sleep deprivation and diminished alertness, to enhance physical and psychological performance, and to enhance survivability rates from physical injury." (Ibid., 329)

The NBIC-projects raise numerous ethical issues, including those of the intended human experiments on brain-machine interfaces, genetic/biochemical engineering of humans, the erosion of basic human rights of soldiers, and the erosion of human responsibility (see e.g. Schummer 2007b). What is more important in the present context, however, is that the military seems to be the driving force behind the move from nano-convergence to NBICconvergence. ${ }^{5}$ That might be economically justified by the fact that the Department of Defense has had the largest share of the NNI budget thus far. However, binding the community of natural, engineering, and social scientists in an allegedly humanistic vein to a human ideal that is modeled after the perfect warfighter, as Roco did, is a severe intrusion of military values into civic society.

Roco found further support for his move from nano-convergence to NBICconvergence in a techno-religious movement called transhumanism. ${ }^{6}$ Again that is no coincidence, because his co-editor and NSF fellow Bainbridge is an influential leader of the transhumanist movement. Transhumanists strive for salvation from world-immanent suffering in a transcendent, so-called post-human, state through step-wise technological transformations. One step is the removal of diseases and aging and the perfection of the human body through some wondrous nanotechnology and genetic engineering. Another step consists in connecting their brains to computers to reach "super-intelligence" and in

\footnotetext{
$5 \quad$ Note that the only official NBIC-report was prepared by RAND's National Defense Research Institute for the National Intelligence Council (2001).

See Schummer 2004c, Schummer 2006, Coenen 2006, and the chapter by Coenen in this volume.
} 
connecting their brains with each other to reach a harmonious "cyber-society" network. In the perfect transhumanist world, their minds have been completely removed from their bodies by being "uploaded" to computers to live the happy life of software.

NBIC-convergence meets the needs of transhumanists because it employs the community of scientists for their specific religious goals. Indeed the NBIC-report includes most of the central features of human enhancement that transhumanists consider as steps towards their salvation. That the military and transhumanist religion here form a strategic alliance might appear strange, but it is hardly an incident that they focus on the same ideas. It is more likely that both have been inspired by the same enhancement ideas that have been circulating for decades in the science fiction literature under the names of cyber punk, postcyber punk, and, more recently, nano-science fiction. Under the heading of nanotechnology, and by the help of the military and transhumanists, these ideas have now become part of the official science policy agenda in the US. The convergence-as-opportunity talk was successful in passing off the specific interests of the military and transhumanists as the proper goals of the society at large.

\section{Analysis: Convergence as a Teleological Concept}

In the previous sections I have analyzed the various uses of the concept of convergence in US reports on nanotechnology. It turned out that the concept is an extremely flexible rhetorical tool to speak about the future, to encrypt goals, and to attribute specific goals to others. In this section I examine the concept of convergence itself to understand the conceptual feature that makes it such a powerful rhetorical tool. I argue that, with the exception of describing the past, convergence is a teleological concept that is about goals and norms rather than about possible facts.

The term "convergence" describes a process over time in which several elements, which are originally at a distance from each other in a certain dimension, move towards each other in the same dimension. As a historical phenomenon, convergence is measurable if the elements are clearly defined and retain their identity over time and if the distances between the elements are measurable at any time. When all the distances between the elements continuously decreased over a certain period and became zero at a certain point, convergence is a plain historical fact. However, neither for nano-convergence nor for NBIC-convergence, any effort at measuring the process of the recent past have been made or commissioned by those who have claimed the recent convergence of disciplines.

Imagine such a measurement was actually made and that it would indicate that the distances between the disciplines, in a certain dimension, have continuously decreased in the recent past, without yet becoming zero, however. Imagine further, that this is not an artifact by the growth of the disciplines in the respective dimension, according to which the intermediate spaces between the disciplines have been filled while the disciplinary centers remained at their former distances. What could we follow from such a move? One could argue that this move is the beginning of a convergence process and that we are currently in the middle of that process. However, any such convergence claim about the recent past and presence is based on anticipating the future, because the move is only part of a convergence process if the convergence will actually be completed. Now one could argue that the past trend allows predicting the future convergence by extrapolation. Although such predictions are frequently made, particularly for the stock market, and at first glance appear plausible by analogy to mechanics, they are usually nothing but guesses without epistemic justification. The reason is that any meaningful prediction of the future by extrapolation from the past requires knowledge of the dynamical features of the system, that is knowledge of the driving forces. Without reasonable assumptions about forces, such predictions are but arbitrary guesses, in mechanics as well as elsewhere. 
The dynamics of disciplines do not occur in a mechanical system, but in a complex social system in which human beings rather than billiard balls are the acting and interacting agents. If there are any equivalents to mechanical forces in that social system, then these are the intentions, desires, and goals of the scientists. Therefore, any meaningful, i.e. nonarbitrary, prediction of the inherent, undisturbed dynamics of disciplines must be based on assumptions about the intentions, desires, and goals of the scientists both individually and collectively, i.e. on assumptions of what scientists want to do in the future and how the individual wishes interact with each other to form collective goals that translate into actions. It follows that whoever makes a meaningful prediction of a future disciplinary convergence, as an undisturbed process, actually makes the claim that disciplinary convergence is the collective goal of the scientists in the present and near future. Again, neither for nanoconvergence nor for NBIC-convergence, any systematic efforts at understanding the individual and collective goals of scientists have been made. Therefore any predictions of the inherent convergence of disciplines in the future are but arbitrary guesses. And because describing the recent past and present as part of a convergence process depends on anticipating the future, any such descriptions of the recent past and present are equally arbitrary guesses.

Now imagine that the future convergence is not considered an undisturbed process of the social system of scientists, but a process that is to be controlled from the outside by science policy. In this case, "convergence" describes neither a possible fact of the past nor the collective goals of the scientists in the present, but a current science policy goal of where the social system of scientists should move to in the future. More precisely, it is a science policy goal about controlling the current collective goals of the scientists. If a science policy maker, in this case, speaks about convergence, then he speaks first of all about his own goals. If he makes predictions about the future convergence of disciplines, then he speaks about his own power in the present and near future to control the collective goals of the scientists. If he actually has the power to impose his goals, then the alleged prediction about science becomes true in the future because of his power rather than because of his predictive capacities.

However, the power of science policy to control the social system of scientists is largely confined to two factors: money and language. By setting funding priorities on projects that require interdisciplinary collaboration, science policy can provide incentives for interdisciplinary projects or temporary networks and centers, hoping that they transform into more stable institutional forms (Schummer 2007a). The influence of this factor is limited by the amount of available money and competing funding sources. The other, more direct way is to convince the scientists to make the science policy goals their own goals. That usually requires an explicit normative debate about goals, about what each party actually wants for the future, about common understandings, differences, and possible compromises. Such a debate has never happened, however. Instead, science policy makers have used the concept of convergence to mask their own goals (as in convergence-by-higher-necessity, Section 2.2), to articulate the alleged goals of the scientists (as in convergence-as-fact of the recent past, present, or future, Section 2.1) and the alleged goals of society (as in convergence-asopportunity, Section 2.3). Since the concept of convergence allows you to talk about your own goals without explicitly stating them and about the goals of others without providing evidence that anybody actually subscribes to these goals, it is a perfect tool to avoid public debate about goals, norms, and values. Whether the rhetorical strategy proves successful or backfires, remains to be seen.

The previous analysis allows drawing the more general conclusions that, with the exception of describing the past, the concept of convergence if applied to social systems in the presence or future is always a teleological concept. That is, any description of the presence or 
prediction of the future as convergence either attributes goals to the social system or expresses the author's own goals.

\section{Conclusion: New Challenges for STS}

The increasing impact of science and technology on the daily life of citizens and the increasing costs of publicly funded $R \& D$ both justify stronger political control and assessment of $R \& D$, which require strategic planning of the future. However, the more power shifts from individual researchers to science policy makers, the more are independent critical studies of science policy required, particularly in a state when fundamental science policy decisions are made by administrators rather than democratically elected politicians. That opens up new areas for science and technologies studies (STS), with their traditional sharpness of analyzing science-society relations.

The present case study on the rhetoric of convergence illustrates the complexity of the task, which includes at least four major challenges for STS. First, when science policy makers develop new programs for the future, they usually start with historical narratives to show that their program is naturally outgrowing from the past, as the claims of the alleged recent convergence illustrate. Critical historical, including scientometric, studies are required to check the accuracy of those claims. Second, science policy ideas are frequently encapsulated in sophisticated rhetoric of book-long reports, as I have illustrated with the various uses of "convergence". Systematic analyses of the rhetorical topoi, including their specific uses and contexts, are required to unravel and criticize their messages. Third, because science policy programs are about future science and technology, they come in a great variety of future talk, including visions, promises, wishes, predictions, predictions of predictions, feasibility and opportunity statements, scenarios, guesses, and teleological concepts, like convergence. We need a systematical conceptual, epistemological, and sociological understanding of these various ways of pointing to the future, including their rooting in the presence and their cultural traditions, in order to understand what they are actually about, to analyze their social dynamics, and to critically assess their claims (see also Grunwald 2006). Fourth, science policy is, like policy in general, about agenda setting and goals, which frequently come, as the example of convergence talk illustrates, in various cryptic forms. We need rhetorical analyses to decode these goals and to identify those who actually hold these goals; and we need sociological and ethical analyses to assess if these goals are socially and morally acceptable.

\section{References}

Canton, John. 1999. The Social Impact of Nanotechnology: A Vision to the Future. In Nanotechnology Research Directions: Vision for Nanotechnology $R \& D$ in the Next Decade. ed. NSTC/IWGN, 178-180. Washington DC.

Coenen, Christopher. 2006. Der posthumanistische Technofuturismus in den Debatten über Nanotechnologie und Converging Technologies. In Nanotechnologien im Kontext: Philosophische, ethische und gesellschaftliche Perspektiven. ed. Alfred Nordmann, Joachim Schummer \& Astrid Schwarz, 195-222. Berlin: Akademische Verlagsgesellschaft.

Coenen, Christopher. Forthcoming. Converging Technologies for Human Enhancement: From Deliberation to Regulation? (in this volume).

Drexler, K. Eric, Christine Peterson and Gayle Pergamit. 1991. Unbounding the Future: The Nanotechnology Revolution. New York: William Morrow.

Goldblatt, Michael. 2002. DARPA's Programs in Enhancing Human Performance. In Converging Technologies for Improving Human Performance: Nanotechnology, Biotechnology, Information Technology and the Cognitive Science, ed. Mihail C. Roco 
and William S. Bainbridge, 337-341. Arlington, VA: National Science Foundation. NBIC-report.

Grunwald, Armin. 2006. Nanotechnologie als Chiffre der Zukunft. In Nanotechnologien im Kontext: Philosophische, ethische und gesellschaftliche Perspektiven, ed. Alfred Nordmann, Joachim Schummer and Astrid Schwarz, 49-80. Berlin: Akademische Verlagsgesellschaft.

National Defense Research Institute for the National Intelligence Council. 2001. The Global Technology Revolution: Bio/Nano/Materials Trends and their Synergies with Information Technology by 2015. Santa Monica \& Arlington.

National Research Council. 2002. Small Wonders, Endless Frontiers: A Review of the National Nanotechnology Initiative. Washington DC: National Academy Press.

Nordmann, Alfred. rapporteur. 2004. Converging Technologies - Shaping the Future of European Societies. Brussels.

NSTC/IWGN. 1999. Nanotechnology Research Directions: Vision for Nanotechnology R\&D in the Next Decade. Washington DC.

NSTC/NSET. 2006 (Feb.). Supplement to the President's FY 2007 Budget. Washington DC.

Roco, Mihail C. 2002. Coherence and Divergence of Megatrends in Science and Technology. In Converging Technologies for Improving Human Performance: Nanotechnology, Biotechnology, Information Technology and the Cognitive Science, ed. Mihail C. Roco and William S. Bainbridge, 79-96. Arlington, VA: National Science Foundation.

Roco, Mihail C. and William S. Bainbridge, ed. 2001. Societal implications of nanoscience and nanotechnology. Kluwer: Dordrecht.

Roco, Mihail C. and William S. Bainbridge, ed. 2002. Converging Technologies for Improving Human Performance: Nanotechnology, Biotechnology, Information Technology and the Cognitive Science. Arlington, VA: National Science Foundation.

Schummer, Joachim. 2004a. Multidisciplinarity, Interdisciplinarity, and Patterns of Research Collaboration in Nanoscience and Nanotechnology. Scientometrics 59: 425-465.

Schummer, Joachim. 2004b. Interdisciplinary Issues of Nanoscale Research. In Discovering the Nanoscale, ed. Davis Baird, Alfred Nordmann and Joachim Schummer, 9-20. Amsterdam: IOS Press.

Schummer, Joachim. 2004c. 'Societal and Ethical Implications of Nanotechnology:' Meanings, Interest Groups, and Social Dynamics. Techne - Research in Philosophy and Technology 8 (2): 56-87 (reprinted in: Nanotechnology Challenges: Implications for Philosophy, Ethics and Society, ed. Joachim Schummer and Davis Baird, 413-449. Singapore: World Scientific Publishing, 2006).

Schummer, Joachim. 2006. Nano-Erlösung oder Nano-Armageddon? Technikethik im christlichen Fundamentalismus. In Nanotechnologien im Kontext: Philosophische, ethische und gesellschaftliche Perspektiven. ed. Alfred Nordmann, Joachim Schummer \& Astrid Schwarz, 263-276. Berlin: Akademische Verlagsgesellschaft.

Schummer, Joachim. 2007a. The Global Institutionalization of Nanotechnology Research: A Bibliometric Approach to the Assessment of Science Policy. Scientometrics 70: 669692.

Schummer, Joachim. 2007b. Identifying Ethical Issues of Nanotechnologies. In Nanotechnologies, Ethics and Politics, ed. Henk ten Have, 79-98. Paris: UNESCO Publishing. 